\title{
RITO DE PASSAGEM AO TERRITÓRIO DA COMICIDADE: elucidações simbólicas à iniciação clownesca.
}

\section{Rite of passage to the territory of comicality: symbolic elucidations to clownesque initiation}

\author{
Ana Elvira Wuo \\ Universidade Federal de Uberlândia - UFU
}

Resumo: O artigo apresenta apontamentos da iniciação clownesca por meio de tramas experimentais aviadas em momentos distintos, as quais culminam no processo ritual da travessia do ator ao território da comicidade. Atravessamentos intrínsecos nas teorizações de Van Gennep, Bergson, Eliade e Turner, alinhavam pontos subjetivos, entrecruzando teoria e práxis, estabelecendo conexões simbólicas, transgredíveis e insólitas.

Palavras-chave: Ritual; Comicidade; Ator; Iniciação.

Abstract: The article presents notes of clowning initiation through experimental plots dispensed at different times, which culminated in the ritual process of crossing the territory of the comic actor. Crossings with the authors Van Gennep, Bergson, Eliade e Turner lined subjective points, crisscrossing theory and praxis establishing symbolic connections.

Keywords: Ritual; Comicality; Actor; Initiation. 


\section{Interpelar o risível no aprendiz}

A interpelação do ridículo e do risível no aprendiz clownesco, num primeiro momento nos parece muito simples e, como exemplo toma-se por empréstimo uma pergunta que Lecoq (2001, p. 59) fez a seus alunos e que em seus desdobramentos ecoa num campo investigativo de extrema complexidade: "Como o clown nos faz rir"?. Em primeira instância, alguns iniciadores relacionam isto ao fato do principiante privar-se do enfrentamento e da exposição ao ridículo criando imobilidade e resistência ao riso do outro. Segundo Bergson (1983, p. 47), o cômico destrói estruturas prontas, tornando-as flexíveis e móveis. Com base nesse princípio, pode-se extrair outra instigante questão relacionada ao campo da comicidade, pois se o riso flexibiliza estruturas, então por quê existe resistência ao risível? Embora 0 apoio conceitual elucide 0 fato teoricamente, a questão prevalece: como flexibilizar o fenômeno na prática? Ao estudar Towsen (1976) percebeu-se, logo de início, um ponto muito esclarecedor neste sentido, pois o mesmo pressupõe no título e na introdução do livro The Clowns uma premissa pluralesca: não existe clown, existem clowns, pela variação de tipos clownescos existentes no mundo todo, no entanto, "Eles são todos palhaços, mas a diferença entre eles é tão fascinante quanto as semelhanças" (1976, p. xi). Por esse motivo, as essências cômicas são múltiplas, variadas e flexíveis (WUO, 2016).

A partir da problematização acima, contatamos uma lacuna na forma de ensino de alguns cursos considerados como modelos de referência na iniciação do clown. A proposta do mestre feita ao principiante, tem o objetivo de ocasionar um arreamento de defesas (termo utilizado em sessões de terapia) criando uma situação de pressão ou de constrangimento no iniciado, isso revelaria intimidades, elucidando situações patéticas nas quais, um tipo desconcertante e acuado de clown apareceria para provocar o riso nos espectadores. No entanto, as nossas questões avançam em outra direção, partindo do pressuposto de que fazer rir é um fenômeno de extrema complexidade e que, para tanto, pressupõe forma de investigação diferenciada em relação ao ensino e a aprendizagem de palhaços.

\section{O processo ritual}

Em nossa pesquisa (WUO, 2016) delineou-se por experimentos aviados em envoltório lúdico ritualístico (e não de arreamento de defesas), conduzindo $o$ iniciado em direção a um rito preambular secreto e subjetivo. Foi eleita a leitura de Van Gennep (1977) como fonte de inspiração numa consonância interlocutora do processo ritual. $O$ rito originário da práxis é um meio profícuo para a iniciação e criação de clown. Van Gennep (1977, p. 160), elucida que rito igualmente sugere e insinua esperança de todos os homens na sua inesgotável vontade de passar e ficar, de esconder e mostrar, de controlar e libertar, nesta constante transformação do mundo e de si mesmo, que está inscrita no verdadeiro viver em sociedade. Dessa forma, o ritual e seus mecanismos básicos são um fenômeno da transformação e passagem do gesto rotineiro ao ato ritual desagregador.

No processo ritual, o desprendimento e o desagregamento de certas qualidades positivas ou negativas humanas envolvem elementos de perdas e ganhos, morte e renascimento, dor e alegria. Revelar e esconder qualidades apontadas na conceituação de Van Gennep (1977, p. 28), 
"quando se perde uma qualidade", geralmente impura, e se adquire outra. $O$ conceito supõe que o sujeito iniciado a um novo mundo passa pela sequência dos ritos de separação, de margem e de agregação com o objetivo de se tornar outro.

O escopo original de nosso estudo, após 20 anos iniciando palhaços em variados contextos da educação formal ou informal, atualmente se aplica em disciplinas de interpretação / atuação no curso de teatro da Universidade Federal de Uberlândia, mantendo a dimensão que engloba um repertório de práticas variadas com o intuito de oferecer ao neófito o trânsito nas diferentes possibilidades de revelar-se comicamente. Deste, foram escolhidos para esta publicação sinteticamente trechos gerais da análise dos ritos: de entrada, margem, passagem, fecundidade, positivo e reforço, desagregação e agregação, mutilação provisória do membro identidade social.

Compreende-se que o "transitar" por meio da prática ritual, há que se retirar de forma simbólica ou concreta o indivíduo da convivência com a humanidade comum, mediante um rito de separação, pois a intenção de todo ato cerimonial é produzir modificação provisória na vida do noviço. Van Gennep elucida que, no corpo ou na alma, modificações outras há também no sentido provisório, como o uso de máscara ou, ainda, pintura no corpo, que marcam diferenciação temporária. Estas desempenham um considerável papel nos ritos de passagem a cada mudança na vida do indivíduo (VAN GENNEP, 1977).
Nesse sentido, com base em estudos do autor citado, é possível compreender que existe em síntese o princípio da pluralidade em relação à variação de formas de início do rito e fazendo uma analogia da teorização ritualística de margem com a máscara clownesca, que também observa-se a separação quando se opera a mutilação provisória do nariz, identidade sócio-pessoal do neófito, quando na vestidura do nariz-máscara vermelha do clown. Nos ritos de margem, o indivíduo não pertence nem ao mundo sagrado nem ao mundo profano, ou ainda pertencendo aos dois mundos em uma posição intermediária, nesse caso com o uso da máscara.

\section{Fragmentos de elucidações simbólicas}

Em resumo, neste tópico o processo inicial apontou a necessidade de conceber uma premissa reflexiva desenvolvida por meio da práxis e intitulada "desforma", princípio flexível e livre, favorecendo a mudança de estado no sentido de romper qualquer pré-elaboração equivocada no ator iniciante, em relação à representação de personagem ou imitação com base em outro palhaço. Van Gennep anuncia que há sempre novos liminares a atravessar, pois a vida do sujeito é formada por um contínuo desagregar-se e reconstituirse, ou seja, mudar de estado e de forma através de um rito positivo, uma vontade, um desejo, uma transposição.

A sequência dos ritos é interpelada por meio de conexões simbólicas. O ritual aqui descrito principia a partir da escolha e da vontade pessoal do ator em passar pela iniciação, a qual é denominada rito positivo. Segundo Gennep, os ritos positivos são atos 
determinados pela vontade, consistindo na separação do neófito de sua vida quotidiana. Outo rito começa no momento em que o aprendiz adentra a sala de trabalho, inicia o período de margem com suspensão da vida comum, passagem ao território desconhecido. Instaura-se uma separação simbólica em que os neófitos devem deixar tudo para trás.

Reportamo-nos à explicação de Eliade (1996), que seria uma síntese fundamental para nosso estudo: separar, desagregar, destruindo as referências, transgredindo, criando um tempo de isolamento, essencial e simbólico, uma ruptura. Segundo Van Gennep (1977, p. 89), "Viver é continuamente desagregar-se". Sugere a abolição de uma imagem arquetípica equivalente a uma regressão ao caos, ao estado que precedia a cosmogonia. Em nosso caso, a abolição ou uma referência anterior a qualquer tipo de figura cômica ou a qualquer outro palhaço era imprescindível.

Principiamos pelo rito de entrada, em que cruzar a soleira da porta de entrada da sala de trabalho é a passagem ao insólito, sendo assim, necessário desconhecer previamente o assunto. "É preciso restabelecer $O$ instante auroral de antes da Criação; no plano humano isto quer dizer que é preciso retornar à 'página branca' da existência, ao começo absoluto", conforme Eliade (1996, p.159), "um desagregar" relacionado à passagem pelas trevas, ao mundo sombrio e desconhecido, à escuridão, ao ventre gerador do processo.

Os ritos de entrada preparam o neófito para desligar o corpo do tempo ordinário, para gestar um novo corpo num outro tempo. Relacionamos esse fato ao que Eliade (2000, p. 159) estabelece como a separação do mundo familiar, em que o neófito é engolido por um monstro, em cujo ventre reina a noite cósmica: é o mundo embrionário da existência, tanto no plano cósmico como no plano da vida humana. Esse território isolado e desconhecido visa oportunizar o contato com outras regiões profundas de nosso ser. Remetemo-nos à história mitológica do isolamento do personagem Jonas no ventre da baleia.

Nas cerimônias no período de margem existem vários ritos de reforço, pertinentes a uma tradição, em diferentes culturas e povos. Por exemplo: cantar, dançar, cortar os cabelos ou raspar a cabeça; o rito de utilização do véu no casamento; utilização de palavras sagradas ou línguas especiais, que algumas vezes inclui "um inteiro vocabulário desconhecido ou não usual da sociedade em geral" (VAN GENNEP, 2001, p. 145). Tais ritos reforçam a permanência, a margem dos iniciados aos territórios de passagem à revelação (VAN GENNEP, 1977). Paralelo este, que foi estabelecido com 0 vocabulário secreto inventado, envolvendo a criação de linguagem e noção conceitual de "desforma" (WUO, 2016, p. 128).

Para a travessia, um grande número de rituais pronuncia a capacidade de construir simbolicamente uma ponte ou uma escada, "uma passagem estreita ou perigosa, motivo corrente tanto nas mitologias funerárias quanto nas iniciáticas" (ELIADE, 1992, p. 147). Tomando como exemplo a travessia da "corda-bamba" na iniciação dos clowns, tarefa esta a ser executada no decorrer do processo ritual (WUO, 2016), que tem o caráter de superação do medo, do encorajamento, do desafio, do desagregar e constituir, que nas palavras de Van Gennep encontra uma consonância de apoio: 
E sempre há sempre novos limiares a atravessar, limiar do verão ou do inverno, da estação ou do ano, do mês ou da noite, limiar do nascimento, da adolescência ou da idade madura, limiar da velhice, limiar da morte e limiar de outra vida- para aqueles que acreditam. (2001, p. 160)

A travessia é um porvir do outro na síntese de Eliade (1959, p. 12): "ao final das provas, o neófito goza de outra existência após a iniciação e integração com o tempo e o espaço imaginário, o da liminaridade", dessa forma 0 processo iniciático limiar potencializa o sítio do envoltório palhacesco transgressor.

O chão da liminaridade conceituado por Turner (1974) inverte a ordem das coisas e interpelaria, em nosso caso, uma alusão ao território de passagem de transvestimento fecundo da máscara ritual para o mundo invertido. Nesse caso, a qualidade-estado da máscara palhacesca é liminar, permite ao iniciado encantado, transitar em um mundo avesso e de cabeça para baixo, por isso o palhaço bagunça a sua vez.

O rito da fecundidade pronuncia a simbolização de que a crença em virtudes mágicas das ostras e das conchas é encontrada no mundo inteiro, da pré-história aos tempos modernos: a comparação da concha marinha ao órgão genital feminino já era conhecida pelos gregos (ELIADE, 1996, p. 123). Rememora o nascimento de Afrodite numa concha, ilustrando esse laço místico entre a deusa e o princípio. Esse simbolismo do nascimento e da regeneração inspira a função ritual das conchas (ELIADE, 1996, p. 129-130). A máscara redonda do clown, pérola vermelha, neste processo, originou-se de uma concha ritual em determinado momento do processo denominado "Visualização da montanha palhaça" em Wuo (2016, p. 136 ) onde o neófito encontra uma pérola vermelha (nariz vermelho) dentro de uma concha. A máscara vermelha redonda, inspirou a função encantatória, delegando à sua vestidura um destino fértil, criativo e mítico. A força agregadora representada por um símbolo de fertilidade manifesta-se em todos os níveis cósmicos.

Na sequência final dos ritos, a condução do iniciado à imagem de uma montanha constitui o rito de agregação à origem (WUO, 2016, p. 136). Outra possibilidade de ligação mítica do "centro do mundo" entre "terra e céu" é a da montanha como uma corporeidade cósmica. A montanha cósmica interliga os territórios de um corpo social conhecido ao corpo insólito, divino e encantado, do ser inusitado, que na iniciação passa a coabitar um corpo clownesco no aprendiz. O símbolo de uma montanha é considerado o simbolismo do centro, que quer dizer o lugar mais alto do mundo, "região pura". Portanto, segundo Eliade, "o cume da montanha cósmica é o umbigo da Terra, o ponto onde começou a criação, fonte de toda a existência" (1996, p. 39).

\section{Considerações prospectivas}

Constatou-se, entre os aprendizes, iniciações variadas e secretamente inusitadas. Também tipos de risos diferentes em plateias diferenciadas. Os neófitos relataram um componente subjetivo mágico associado à iniciação do "ser clown". O processo ritual foi de escamoteação e mutilação pessoal 
patética, com pluralidade e variedade criativa, em cada iniciado. Isso provém de rupturas, contradições marginais que, desconstruindo convenções sociais, por meio do uso da máscara, mutila a rigidez no si mesmo, lançando ao abismo o indivíduo humanamente social por meio do riso inusitado produzido pela plateia.

Poucos aprendizes resistiram ao atravessamento da soleira da porta, entrada ritual, por conta do medo da exposição e queda ao ridículo. Estes, arraigados por préjulgamentos e valores cristalizados, desautorizaram a travessia à comicidade, pois a abnegação dos conceitos duros, como desprender um esparadrapo na pele, é extremamente doloroso por ser resistível. Compreendeu-se que, ao provocar o riso no público, aceita-se o ridículo como espaço público multi-corporal do traspassamento à liminaridade cômica e de renúncia a valores relacionados à aparência física normativa.

A qualidade apreendida, intrínseca à mobilidade transgressiva assimilada pelo ator iniciado à máscara da comicidade, rompe o lacre da resistência preambular em meio a travessia dos territórios de passagem aos espaços em branco e insólitos.

Recebido em: 26/04/2018

Aceito em: 20/06/2018

\section{Referências Bibliográficas}

BERGSON, Henri. O Riso: ensaio sobre a significação do cômico. $2^{\mathrm{a}}$. Ed. Zahar, Rio de Janeiro, 1983.
ELIADE, Mircea. Aspectos do mito. Trad. Manuela Torres. Perspectivas do homem. Lisboa: Edições 70, 2000.

ELIADE, M. Imagens e símbolos: Ensaio sobre o simbolismo mágico-religioso. Tradução Sonia Cristina Tamer. Martins Fontes, São Paulo, 1996.

ELIADE, Mircea. O Sagrado e o Profano: a essência das religiões. Trad. Rogério Fernandes. Martins Fontes, São Paulo, 1992.

ELIADE, Mircea. Initiation, rites, sociétés secrètes: naissances mystiques. Essai sur quelque types d'initiation. Paris: Galimard, 1959.

LECOQ, Jacques. The moving body: the teaching creative theatre. Translated from Le corps Poétique by David Bradby. A theatre Arts Book. Routledge. New York, 2001.

TOWSEN, John. H. Clowns. New York: Hawtorn, 1976.

TURNER, V. W. O processo ritual: estrutura e antiestrutura. Antropologia 7. Petrópolis: Vozes, 1974.

VAN GENNEP, Arnold. Os ritos de passagem: estudo sistemático dos ritos da porta e da soleira, da hospitalidade, da adoção, gravidez e parto, nascimento, infância, puberdade, iniciação, coroação, noivado, casamento, funerais, estações, etc. Tradução de Mariano Ferreira, 2.ed. Petrópolis: Vozes, 2001.

VAN GENNEP, Arnold. Os ritos de passagem. Ed. Vozes, Petrópolis, 1977.

WUO, Ana E. Clown: "desforma", rito de iniciação e passagem. Doutorado em Artes da Cena, UNICAMP, Campinas, 2016. 